\title{
Percepção da enfermagem acerca do acompanhante no cuidado à criança hospitalizada
}

\author{
Nursing perception about the companion in the care of hospitalized children
}

Mychelle Almeida Salgado a, Isaiane Santos Bittencourt ${ }^{\mathrm{b}}$, Mykaelle Almeida Salgado ${ }^{\mathrm{a}}$, Gilvânia Patrícia do Nascimento Paixãoc, Christielle Lidianne Alencar Marinhod, Chalana Duarte de Sena Fraga ${ }^{\mathrm{e}}$

\footnotetext{
a Enfermeira graduada pela Universidade do Estado da Bahia (UNEB), Campus VII. Senhor do Bonfim, BA, Brasil.

bEnfermeira. Mestre em Enfermagem e Saúde. Professora Assistente da UNEB/Campus VII. Senhor do Bonfim, BA, Brasil.

cEnfermeira. Doutora em Enfermagem. Professora Assistente da UNEB/Campus VII. Senhor do Bonfim, BA, Brasil.

¿Enfermeira. Mestra em Hebiatria. Professora Auxiliar da UNEB/Campus VII. Senhor do Bonfim, BA, Brasil.

e Enfermeira. Mestre em Enfermagem. Professora Auxiliar da UNEB/Campus VII. Senhor do Bonfim, BA, Brasil.
}

RESUMO Objetivo: Conhecer a percepção da equipe de enfermagem sobre a presença e participação do acompanhante no cuidado a criança hospitalizada.

Materiais e Métodos: Estudo descritivo e exploratório, com abordagem qualitativa, realizado com 11 profissionais de enfermagem por meio de entrevistas semiestruturadas, cujos resultados foram tratados através da análise temática, proposta por Bardin. O projeto foi aprovado pelo Comitê de Ética da UNEB, parecer no 823.653.

Resultados: A partir da análise dos dados emergiram três categorias "Percepção da enfermagem sobre o acompanhante: benefícios e transtornos"; "Participação do acompanhante na assistência à criança: aspectos afetivos, cuidados do cotidiano e complexos" e "Influência da presença do acompanhante no cuidado de enfermagem".

Conclusão: Os profissionais, em sua maioria, consideram os benefícios da presença do acompanhante durante a hospitalização da criança, entretanto percebem o acompanhante como realizador do cuidado, e não como alguém que também demanda cuidado. Nessa perspectiva, torna-se primordial compreender os impactos da hospitalização tanto para a criança como para os pais/responsáveis.

Palavras-chave: criança hospitalizada; acompanhantes de pacientes; equipe de enfermagem.

ABSTRACT

Objectives: To know the perceptions of the nursing staff about the presence and participation of the caregiver in the care of hospitalized children.

Materials and Methods: Exploratory, descriptive study with a qualitative approach, carried out with eleven nursing professionals through semi-structured interviews. Results were interpreted through thematic analysis proposed by Bardin. The project was approved by the Ethics Research Committee of UNEB under the number 823.653.

Results: From the data analysis three categories emerged "Perception of nursing about the caregiver: benefits and disorders", "Caregiver's participation in child care: affective aspects, daily and complex care" and "Influence of the caregiver's presence in nursing care".

Conclusion: The professionals, for the most part, consider the benefits of the caregiver presence during the child's hospitalization. However, they are perceived as care providers, not as someone who also requires care. In this perspective, it is essential to understand the impacts of hospitalization for both the child and the parents/guardians.

Keywords: hospitalized child; caregivers; nursing team.

\section{Correspondência:}

ISAIANE SANTOS BITTENCOURT

Rua Henrique Rocha 379 - Centro

48905-120 Juazeiro, BA, Brasil

E-mail: isaianesbb@hotmail.com 


\section{INTRODUÇÃO}

A criança e o adolescente são seres biopsicossociais em crescimento e desenvolvimento, e como tal, devem ser atendidos em toda a sua individualidade e necessidades básicas de nutrição, educação, socialização e afetividade ${ }^{1}$. Durante esse processo, a criança está propensa a apresentar algumas doenças, necessitando de uma internação.

A hospitalização da criança é um evento capaz de gerar novas necessidades sociais, físicas e afetivas tanto para o menor como para a família. Geralmente a internação tende a uma experiência negativa ${ }^{2}$, por mais simples que seja o motivo, gerando sentimentos de medo, angústia, ansiedade, insegurança e estresse ${ }^{3}$. Diante deste evento, a assistência à criança hospitalizada demanda um cuidado humanizado e integral, responsável por reconhecer sentimentos, vontades e necessidades, visando minimizar as adversidades do momento de internação e ajudar o menor a aceitar com mais tranquilidade os procedimentos ${ }^{4}$.

Para que essa assistência seja possível, é preciso que a equipe de enfermagem tenha sensibilidade para entender o indivíduo e perceber os múltiplos fatores que envolvem o cuidado e como a criança e a família vivenciam o período de internação. Além da competência técnico-científica para atender às necessidades decorrentes do diagnóstico e terapêutica, deve-se utilizar de subsídios que reflitam acerca das próprias ações a fim de possibilitar o estabelecimento de relações interpessoais efetivas para compreender pais e filhos como pessoas dotadas de demandas de cuidado ${ }^{5}$. Alguns instrumentos vem sendo utilizados como forma de aliviar as tensões causadas pela internação, pela mudança de ambiente e por estar cercada por pessoas estranhas, sendo eles o brinquedo terapêutico ${ }^{6-8}$, musicoterapia, estabelecimento de vínculo entre profissional-criança-acompanhante, e principalmente a presença do acompanhante na unidade $^{9}$.

Vale ressaltar que cuidar do ser humano não é apenas cuidar do seu corpo, mas sim de seu universo, que inclui a família e o contexto social no qual está inserido. Acreditase que para existir uma hospitalização humanizada é importante a incorporação da família/acompanhante no cuidado à criança ${ }^{10}$. A participação do acompanhante e uma boa interação com a equipe de enfermagem são essenciais durante a internação da criança no processo terapêutico, entretanto é comum acontecer desarmonia na relação do acompanhante com a equipe, caracterizada pela falta de diálogo, ansiedade e estresse provocados pela doença e pelo cansaço físico ${ }^{11}$. O acompanhante durante a hospitalização da criança continua a prestar-lhe cuidados tão essenciais quanto a equipe de enfermagem, sendo eles de natureza afetiva, de proteção, e de ajuda para superação da internação. Assim, torna-se um aliado dos profissionais no auxílio dos procedimentos, no suporte ao tranquilizar o paciente e nas informações importantes sobre a criança ${ }^{12}$.

A equipe de enfermagem deve considerar que a presença do acompanhante é responsável por fatores positivos relacionados à estabilização da saúde do paciente pediátrico, promovendo maioria das suas necessidades de conforto e segurança, além de contribuir com informações significativas a respeito do paciente, o que acaba favorecendo a tomada de decisão de quando realizar o procedimento ${ }^{10}$.

Tendo em vista os benefícios da participação do acompanhante na assistência à criança, associado com a escassez de pesquisas que abordam o tema, pergunta-se: Qual a percepção da equipe de enfermagem sobre a presença e participação do acompanhante no cuidado a criança na unidade de internação pediátrica? O presente estudo teve como objetivo, conhecer a percepção da equipe de enfermagem sobre a presença e participação do acompanhante no cuidado a criança hospitalizada.

\section{MATERIAIS E MÉTODOS}

Estudo descritivo e exploratório, com abordagem qualitativa, realizado com profissionais de enfermagem da clínica pediátrica de um hospital público na cidade de Petrolina-PE.

O referido hospital é uma instituição destinada ao atendimento materno-infantil de média e alta complexidade, pertencente à rede estadual de saúde, possui um total 201 leitos. Possui uma clínica pediátrica com 9 enfermarias nas quais ficam dispostos 46 leitos. As principais causas de internamentos são por afecções do aparelho respiratório, doenças infecciosas e parasitárias, morbidades gastrointestinais, patologias cirúrgicas e alterações provenientes do período perinatal. Neste setor, atuam 8 enfermeiros e 33 técnicos de enfermagem.

A amostra do estudo foi composta por 11 profissionais, a saber foram quatro enfermeiras e sete técnicas de enfermagem. A seleção da amostra ocorreu de forma intencional, as pesquisadoras compareceram à instituição nos turnos matutino, vespertino e noturno e entrevistaram os profissionais que atendiam os seguintes critérios de inclusão na pesquisa. A coleta das informações ocorreu até a saturação dos dados, que ocorreu ao se observar a redundância e repetição de informações, o que indicou que o acréscimo de novos sujeitos não contribuiria significativamente para o aumento de informações ${ }^{13}$. As participantes da pesquisa desenvolviam suas atividades nos três turnos de trabalho e foram esclarecidas quanto aos objetivos e a metodologia da pesquisa. 
Foram selecionados para a amostra profissionais de enfermagem com vínculo no hospital estudado, estando em pleno exercício profissional e que aceitaram participar voluntariamente da pesquisa. Os critérios de exclusão adotados foram profissionais com menos de um ano de vínculo na clínica pediátrica e a recusa em participar do estudo.

A coleta de dados ocorreu no período de janeiro à março de 2016, por meio de entrevistas semiestruturadas individuais, com o apoio de um formulário semiestruturado, composto de duas partes. A primeira, contemplando dados de caracterização do participante, com as seguintes informações - idade, sexo, formação profissional e participação em capacitações, período de formação e de trabalho na instituição. Na segunda parte, contemplava as questões norteadoras referente aos cuidados prestados pelos acompanhantes: Qual a percepção sobre o acompanhante da criança hospitalizada? Quais os cuidados que o acompanhante presta na internação? Quais as vantagens e desvantagem de ter o acompanhante? Dentre os cuidados realizados pelo acompanhante, quais necessitam da supervisão de enfermagem? Como é cuidar da criança na presença do acompanhante?

Primeiramente, foi realizado um estudo piloto com técnicas de enfermagem na clínica pediátrica do hospital de Senhor do Bonfim-BA, para identificar possíveis falhas, como: questões mal elaboradas ou dificuldades de leitura deste instrumento de coleta. Considerando ser importante testar o instrumento, com o intuito de desenvolver os procedimentos de aplicação; testar o vocabulário empregado nas questões e assegurar-se de que as questões contribuirão com o objeto de estudo ${ }^{13}$.

Após o piloto, iniciou-se a coleta de dados em dia e horário agendados de acordo com as disponibilidades dos profissionais. As falas foram gravadas com autorização dos sujeitos e posteriormente transcritas na íntegra. A organização dos dados foi realizada de acordo com a técnica de Análise de Conteúdo Temática, proposta por Bardin. Este Método utiliza as etapas de pré-análise, exploração do material, tratamento dos resultados obtidos e interpretação, visando atingir os objetivos do estudo ${ }^{14}$.

A Pré-análise foi o momento de organização do material, que consistiu na escolha dos documentos a serem analisados, e retomada das hipóteses e dos objetivos iniciais da pesquisa. $\mathrm{Na}$ exploração do material foi feita a realização de reajustes finais, necessários ao processo de organização da análise, dando origem as categorias que são expressões ou palavras significativas em função das quais o conteúdo de uma fala será organizado. E por fim, o tratamento dos resultados obtidos e interpretação, que foi estabelecido através da articulação entre os resultados e a experiência das autoras. Posteriormente, a interpretação desses dados foi subsidiada por referências científicas para atingir os objetivos da pesquisa ${ }^{14}$.

Os participantes assinaram o Termo de Consentimento Livre e Esclarecido (TCLE) e eles foram identificados por um "E" acompanhada do número da entrevista, para Enfermeiras, como exemplo E1, E2, E3... e "TE" também acompanhada do número das entrevistas, TE1, TE2, TE3... para os técnicos de enfermagem, com a finalidade de manter o anonimato dos informantes. O estudo respeitou a Resolução 466/2012 do Conselho Nacional de Saúde (CNS) e foi aprovado pelo Comitê de Ética em Pesquisa da Universidade do Estado da Bahia, sob o parecer no 823.653.

\section{RESULTADOS E DISCUSSÃO}

No total, participaram do estudo onze profissionais de enfermagem, sendo sete técnicas de enfermagem, três enfermeiras e um enfermeiro. A maioria do sexo feminino (10), idade variou entre 23-51 anos, e a função desempenhada que predominou foi a assistência, sendo dez profissionais, e um a gerência. Com relação ao tempo de formação variou entre 2-26 anos e tempo de trabalho na instituição entre 1-6 anos. Segundo as especializações, somente as enfermeiras possuem e referiram ter especializações em neonatologia e pediatria, e além dessas alguns possuíam a de enfermagem do trabalho e de saúde pública.

A partir da leitura das falas dos sujeitos, os dados foram organizados, resultando em três categorias de análise: Percepção da enfermagem sobre o acompanhante: benefícios e transtornos; Participação do acompanhante na assistência à criança: aspectos afetivos, cuidados do cotidiano e complexos; Influência da presença do acompanhante no cuidado de enfermagem

\section{Percepção da enfermagem sobre o acompanhante: benefícios}

Nesta categoria, foi possível evidenciar a percepção dos profissionais de enfermagem com relação ao acompanhante na internação pediátrica. A maioria dos entrevistados descreve positivamente ao apresentar os benefícios que são gerados, sendo eles: diminui a demanda de trabalho e aumenta o vínculo mãe-filho.

O acompanhante contribui para diminuir a demanda de trabalho da enfermagem. Haja vista que a equipe de enfermagem possui um conjunto de responsabilidades com a criança internada, que varia em níveis de complexidade, desde a higiene corporal do paciente como o banho e troca de lençóis, realização de procedimentos invasivos 
como punção venosa, administração de medicamentos, sondagem gástrica/enteral, cateterismo vesical, gavagem, troca de curativos, anamnese e exame físico, dentre outros. Além dos cuidados de natureza intersubjetiva com a comunicação empática, utilização da recreação e ludicidade, envolvimento ativo com criança e responsável no processo de internação. Como pode ser observado nos seguintes fragmentos:

Importante, ajuda bastante. Eu já trabalhei no hospital 10 anos, e não tinha acompanhante, eu sei como é ruim. A gente tinha que dá conta de tudo, pelo menos a mãe fica ao lado. (TE7)

É importante, porque a demanda de criança é muita, então a gente não tem como está no pé. Não tem como dá total assistência, quer dizer, damos, mas é importante porque são muito e não dá pra dá atenção a todos ao mesmo tempo. (TE6)

[...] pela quantidade de profissional a gente não tem como está 24 horas nos leitos, e pela quantidade de leitos, entendeu? (TE2)

Segundo os profissionais de enfermagem a presença do acompanhante na unidade pediátrica é importante, visto que a quantidade de crianças internadas é grande e eles não conseguem fornecer uma assistência integral a todos. Uma depoente ainda faz referência ao período em que não havia o acompanhante na unidade e que além dos cuidados técnicos de enfermagem, ofereciam cuidados de higiene e alimentação.

A criança requer cuidados de alimentação, higiene, conforto, segurança, medicação, carinho, entre outros. Quando o acompanhante está presente na unidade para proporcionar a atenção às necessidades afetivas, a equipe de enfermagem tem um auxilio no desenvolvimento da assistência integral. Porém, na sua ausência, a equipe de enfermagem deve incorporar a assistência emocional à criança, de modo a garantir a continuidade no recebimento da afetividade ${ }^{15}$.

É importante que os profissionais ao fornecerem uma assistência à criança hospitalizada adotem uma atitude integral capaz de articular as necessidades biológicas, sociais e afetivas. A participação e envolvimento ativo da equipe de saúde com os pais/responsáveis deve ser utilizado como uma estratégia para propiciar uma internação humanizada e menos traumática ${ }^{16}$.

Os profissionais relacionaram ainda o acompanhante como alguém que ajuda a criança a se sentir acolhida pela instituição, além de aumentar o vínculo mãe-filho, nos relatos apresentados a seguir:
Assim, na maioria das vezes, o acompanhante ajuda, porque é um ambiente hospitalar e a criança se sente já fora do seu domínio, fora da sua área, e com a mãe, um pai, uma avó, um tio, eles se sentem mais acolhidos pela instituição, [...] por ter uma pessoa que ela conhece ao lado dela. (E4)

[...] sem se falar do calor humano, né, a mãe precisa demais, e o filho precisa da mãe. (TE5)

A presença do acompanhante na unidade ajuda a diminuir as dificuldades de adaptação da criança na instituição, bem como manter o vínculo mãe-filho, visto que o vínculo afetivo é muito importante para a recuperação da criança ${ }^{17}$.

Neste contexto, o profissional de enfermagem deve contextualizar sua assistência sob uma perspectiva de interação com a família ao adotar estratégias para facilitar a adaptação tanto da criança como do acompanhante ao processo de hospitalização.

\section{Percepção da enfermagem sobre o acompanhante: transtornos}

Nesta categoria, encontra-se a visão do acompanhante como alguém que pode não contribuir com a assistência de enfermagem. Sendo uma fala apresentada apenas por um participante do estudo, que percebe o acompanhante como um empecilho.

Ao mesmo tempo em que os discursos denotam uma postura favorável à presença dos acompanhantes durante a internação, há um depoente que refere que alguns acompanhantes dificulta o trabalho da equipe:

Acho importante o papel do acompanhante na internação da criança. Porém tem uns acompanhantes que dificultam o trabalho da equipe. (TE4)

Mesmo o profissional de enfermagem achando o papel do acompanhante na internação infantil importante, refere que alguns acompanhantes dificultam o trabalho da equipe.

A identificação por parte da equipe de enfermagem do acompanhante como um agente responsável por atrapalhar o trabalho executado, pode ser resultado da dificuldade dos familiares em compreender e lidar com a doença e a hospitalização. O que pode gerar alterações na dinâmica pessoal e familiar, há uma mudança brusca na rotina e o cotidiano de exames, procedimentos invasivos e dolorosos atrelados às alterações da condição clínica da criança podem funcionar como elementos estressores, contribuindo para a família reagir de uma forma diferente do esperado pela equipe. O desenvolvimento de ações empáticas, com uma comunicação efetiva e o estabelecimento de vínculo são 
elementos necessários para apoiar os acompanhantes e auxilia-los neste processo ${ }^{18}$.

Em estudo realizado com familiares de crianças hospitalizadas foi identificado quatro elementos responsáveis por facilitar a participação dos acompanhantes no cuidado à criança, sendo eles: Ter acesso às informações sobre a condição clínica do paciente; receber orientações estruturadas de como participar dos cuidados à criança; ser tratado com ações humanizadas e possuir melhor conforto físico para o cuidador ${ }^{19}$.

É essencial que os profissionais de enfermagem tenham conhecimentos científicos sobre a importância da relação acompanhante/criança para o desenvolvimento infantil. Dessa forma, os profissionais passam a enxergar o acompanhante não como uma interferência negativa na sua assistência, mas como um sujeito colaborador e participante do cuidado.

\section{Participação do acompanhante na assistência à criança: aspectos afetivos, cuidados do cotidiano e complexos}

Esta categoria descreve os cuidados prestados pelo acompanhante durante a internação da criança que vai desde suporte emocional e afetivo até cuidados mais técnicos que necessitam da supervisão de enfermagem.

Como pode ser observado nas falas abaixo, o suporte emocional, afetivo e segurança é tido como cuidados prestado pelo acompanhante a criança hospitalizada:

E no sentido de ajudar, de dar os cuidados, e até proximidade com a criança no relacionamento, o amor, né. A criança se sente mais confortável, mais aconchegante, mais tranquila. (E1)

\section{[...] atenção, carinho. (TE1)}

[...] além do apoio psicológico, que eu acho muito importante ele estar, porque ele passa segurança pra criança. (TE4)

Os familiares/acompanhantes exercem papel fundamental no contexto da internação infantil, já que representam a referência sobre segurança, carinho, afeto, além de apoio, imprescindível para o enfrentamento da situação desafiadora que é a doença e o tratamento ${ }^{17}$.

A presença do acompanhante em tempo integral, junto à criança, na unidade de internação pediátrica, beneficia a ambos, por proporcionar interações capazes de reduzir os estressores e favorecer o reequilíbrio do processo saúdedoença $^{12}$.

No que se refere aos cuidados do cotidiano, os relatos demonstram:
De dá banho, de avisar a equipe de enfermagem se tá com dor, se tá com a temperatura alta, só esses cuidados que a acompanhante tem. (E3)

Eles trocam fralda, qualquer coisa que ele vê de errado na criança, se vomitar, eles chamam pra perguntar, e a gente orienta eles. (TE3)

[...] Tem a questão da nebulização que a gente instala e quem administra são eles. (E4)

[...] quando a criança tá com febre ela chama a gente, ela quem dá banho na criança, ela quem acompanha, ela quem dá comida. Independente daquelas crianças que a gente tem que dá por sonda, por sonda quem dá é a gente [...] (TE5)

No que concerne às atividades realizadas pelo acompanhante no hospital, a equipe de enfermagem salienta nos depoimentos que são os cuidados mais simples, que não há necessidade de conhecimento técnico, como vigilância, banho, alimentação, troca de fralda, nebulização e outros, referindo ser cuidados semelhantes ao do domicilio. No entanto, é importante que a mãe esteja segura para realizar essas tarefas, e em caso de dúvidas, recebam a orientação da equipe, uma vez que os cuidados mais simples, quando prestado no hospital, podem assumir novas características com o uso de dispositivos tecnológicos, as quais se tornam complexos como manipular sondas para aspiração e alimentação, podendo permear barreiras emocionais diante dos procedimentos ${ }^{18}$.

O acompanhante necessita de orientações que o habilite a assistir melhor a criança e possibilita suporte para a realização de alguns cuidados, afim de impedir que piore seu quadro clínico ${ }^{19}$.

A participação dos acompanhantes nos cuidados prestados às crianças hospitalizadas deve ser vista como uma contribuição, ou parte integrante no planejamento dos cuidados da criança, por ser considerada como um fator importante para a manutenção de laços familiares ${ }^{17}$.

Nos depoimentos dos entrevistados a seguir, fica evidenciado que os cuidados considerados como mais complexos pelos profissionais, são realizados pelos acompanhantes, mas sob a supervisão da enfermagem:

Se o paciente tiver sonda, e que a mãezinha for dá a dieta, se for um paciente que já usa sonda em casa, a gente fica sempre acompanhando esse procedimento, vê se realmente a mãe está fazendo isso direito, se está lavando a sonda depois da dieta. [...] Paciente que é traqueostomizado, precisa de um acompanhante, são paciente que geralmente são dependentes, e vão com traqueóstomo pra casa, então, precisa que a gente sempre esteja orientando. O que a mãe vai ter que fazer em casa, então sempre orientar, e ficar analisando se estão fazendo corretamente, a aspiração. (E3) 
Na hora da alimentação, que pode broncoaspirar. Crianças pequenininha, né? Inclusive temos criança aqui com traqueostomo e a mãe [...] precisa muito da gente, pra gente orientar. (TE5)

Na verdade o cuidado que realizamos em parceria com o acompanhante é para pacientes crônicos, a equipe todinha dá suporte e treinamento para que essa mãe ou cuidador dê prosseguimento na residência. (E2)

Diante das falas, percebe-se que os profissionais dão prioridades a supervisão das crianças que apresentam doenças crônicas ou que necessitará de cuidados especiais nos domicílios, nestas situações buscam treinar o acompanhante com fins de capacitá-los para a realização de determinados procedimentos, como a gavagem e aspiração de traqueostomia. Esta supervisão é relevante para direcionar a família no desenvolvimento de habilidade para a realização de novo cuidado à criança e contribuir para a execução de uma ação segura com menor possibilidade de consequências negativas.

Os avanços tecnológicos ocorridos geraram um aumento do número de crianças com doenças crônicas que são cuidadas no domicílio. Para se adaptarem a esta nova realidade, a família teve de se tornar suficientemente esclarecida ao ponto de saber reconhecer sintomas e ajustar-se ao novo estilo de vida. Para tanto, os familiares das crianças com essas doenças necessitam de mútua confiança, e eles esperam que seus conhecimentos sejam validados, e sua participação no cuidado com a criança seja aceita $^{12,20}$.

A prática do compartilhamento com o acompanhante ocorre mediante a necessidade de se realizar cuidados mais elaborados após a alta hospitalar, por meio do que a enfermagem denomina de treinamento. A troca de saberes entre os profissionais e o acompanhante é essencial para a continuidade do cuidado de sua criança em domicilio, bem como a promoção da saúde ${ }^{12}$.

O cuidado da enfermagem no contexto do acompanhante deve estar direcionado para além da troca de conhecimentos sobre ações de técnicas, como a realização de aspiração e gavagem. Deve abarcar a recreação e ludicidade como estratégias facilitadoras do internamento. Ao possibilitar momentos de descontração e alivio do estresse gerado por procedimentos e exames ${ }^{18}$.

Para tanto, a equipe de enfermagem deve compreender a necessidade de uma abordagem diferenciada ao público infantil, com a preparação para exames e procedimentos através do brinquedo terapêutico e abordagem adequada à fase de crescimento e desenvolvimento com envolvimento ativo do acompanhante ${ }^{8}$.

\section{Influência da presença do acompanhante no cuidado de enfermagem}

Esta categoria evidencia a influência da presença do acompanhante no cuidado de Enfermagem. Mediante variadas vivências, a equipe apresenta visões divergentes sobre a presença do familiar durante a realização de procedimentos. Alguns referem que a presença do acompanhante não interfere no trabalho da equipe, como pode ser observado nos depoimentos:

Bem, pra mim, como enfermeira não tem diferença, o meu cuidado a criança com o acompanhante e sem o acompanhante, porque o compromisso tem que ser igual, e você gostar do que faz, ter amor por aquela criança. Independente dela estar sozinha ou não. É válido que uma criança só, requer mais atenção, mais cuidado, do que uma criança que está com acompanhante. Mas a assistência de enfermagem em si, não muda. (E1)

[...] Se você é segura do que você faz e não tem medo, isso ali não the atrapalha. (E3)

Eu acho que não tem diferença de cuidar da criança na presença ou na ausência do cuidador. Você deve cuidar do paciente da mesma forma. (TE4)

Outros profissionais de enfermagem apontam a importância em manter o acompanhante durante os procedimentos, porque geralmente a criança se sente segura, fica mais calma, colaborativa:

Normal, eu acho até melhor, porque você dá de cara com a criança, ela nunca Ihe viu, ela fica assusta, e com o acompanhante do lado, ela vai conversando com ela, e acalma a criança. (TE6)

[...] a gente pra criança é estranha, pra pegar um acesso, fazer alguma coisa com ela, com a mãe, o acompanhante ao lado ela fica mais segura. (TE6)

A mãe auxilia quando vai puncionar o acesso, a segurar, a realizar curativo. (E1)

A presença do acompanhante junto da criança é significativa, uma vez que o acompanhante é uma fonte de apoio tranquilizador para a criança, dando suporte emocional e passando segurança para a criança ${ }^{21}$.

Alguns entrevistados referiram que a presença do acompanhante é tranquila, mas em procedimentos traumáticos, punção e sonda, podem atrapalhar. Tal evidência pode ser observada nos fragmentos seguinte: 
Tranquilo, a gente se sente bem confortável em trabalhar junto da mãe, normalmente são mães compreensíveis, mas na verdade quando lida com a criança é muito difícil, a mãe tem aquele instinto protetor, e as vezes pode prejudicar na hora de um procedimento traumático como punção, passagem de sonda e outros. (E2)

Pra mim não incomoda, [...] mas teve um pai que chegou na hora que eu ia pegar uma jugular, ele não gostou e levou o menino, tive que acionar o conselho tutelar, que não aceitava que a gente estivesse furando o filho dele todo, [...] não entende o trabalho da equipe. (E3)

[...] muitas vezes a ansiedade desse parente faz com que o serviço e a assistência desse paciente não ande como deveria. Passa essa ansiedade para o paciente e termina deixando a equipe, muitas vezes, irritada por certas cobranças. (E4)

Os discursos revelam algumas dificuldades encontradas pela equipe de enfermagem durante a realização de procedimentos, principalmente quanto à resistência do acompanhante em determinados procedimentos, como a punção venosa. Os profissionais acreditam que os pais tornam o ambiente apreensivo pela superproteção do filho, com demonstração de insegurança e ansiedade, prejudicando o trabalho da equipe e o tratamento da criança.

No cotidiano do hospital, dentre os procedimentos de enfermagem, a realização de punção venosa é um dos que desencadeia maior sentimento de dor na criança, contribui para tornar o momento traumático para criança causando sofrimento também nos familiares ${ }^{22}$.

Importa que a criança, compreenda a importância da realização de um procedimento, mesmo que doloroso e desconfortável, para a recuperação da saúde, neste sentido, os profissionais devem orientar tanto a criança quanto a família/acompanhante, preparando para o procedimento a fim de minimizar os medos que perpassam pela criança e tornando a hospitalização menos traumática ${ }^{22}$.

Por fim, um depoente referiu não se incomodar com a presença do acompanhante, visto que pode ser um momento de aprendizado para o mesmo.

[...] não tem incomodo nenhum. É bom pra gente e bom pra elas. Além delas ter o conhecimento, elas aprendem. Tem mães que passam muito tempo aqui na unidade, tem mães que aprendem a aspirar, a gente ajuda elas a aspirar, orienta para não contaminar. A presença dela é muito importante pra gente e pra criança também, porque elas ajudam. Tem muitas crianças dependentes da mãe, e até da gente mesmo. (TE5)
Além da presença do acompanhante durante procedimento invasivo ser fonte de segurança, proteção e apoio, é um momento de aprendizagem. A criança e o acompanhante precisam receber informações e ensinamentos específicos para continuar com o cuidado após a alta.

O processo de aprendizagem de cuidados de saúde durante a hospitalização é valorizado pelos acompanhantes e profissionais para a continuidade dos cuidados da criança no domicílio, enfatizando a dimensão da comunicação para a resolução de dificuldades ${ }^{23}$.

\section{CONSIDERAÇÕES FINAIS}

Estudar sobre a participação do acompanhante no cuidado à criança hospitalizada em uma clínica pediátrica, sob a ótica dos profissionais de enfermagem, permitiu conhecer a percepção da equipe de enfermagem sobre a participação e presença do acompanhante. A equipe de enfermagem percebe como importante a permanência do acompanhante na unidade, visto que sua presença gera benefícios a ambos: diminui a elevada demanda de trabalho; ajuda no cuidado básico, na avaliação de alguma intercorrência; aumenta o vínculo mãe-filho; proporciona apoio emocional e segurança. Contudo, também pode gerar desconforto para a equipe, especialmente durante a realização de procedimentos traumáticos que geram dor e sofrimento na criança.

O acompanhante quando inserido na unidade pediátrica, além de prestar cuidados emocionais, realizam cuidados próximos aos realizados no domicílio, como a vigilância, higienização, alimentação, dentre outros. Os acompanhantes necessitam de informação, saberem dos porquês dos procedimentos e medicamentos, bem como a forma correta de manuseio da criança durante o banho e alimentação no leito e ter a opção de prestar este cuidado ou deixar que um profissional o faça.

Para que ocorra a integração acompanhante/equipe, a mesma deve discutir com o acompanhante a participação deste no cuidado e fornecer-lhe informação, aconselhamento e suporte para realizá-lo. Assim sendo, não basta informar ou treinar, mas é importante dar-lhe condições e suporte teórico e emocional para cuidar de sua criança em domicilio.

Os profissionais percebem o acompanhante como realizador do cuidado, e não como alguém que também demanda cuidado. Nessa perspectiva, torna-se primordial olhar o acompanhante como objeto do cuidado. Faz se necessário que as unidades pediátricas propiciem um momento de troca entre família e equipe de enfermagem por meio de grupos de apoio, abordagem interdisciplinar e educação continuada, a fim de que a inserção do 
acompanhante seja facilitada, e a internação infantil não seja vista apenas como um momento de sofrimento, mas que sirva de crescimento para a criança, acompanhante e equipe.

Neste sentido, aponta-se como limitação do estudo a profundidade das perguntas do instrumento de coleta dos dados, o que pode dificuldar a interpretação dos dados obtidos, haja vista a influência da percepção do pesquisador. Apesar disto, o estudo apresenta contribuições para o cuidado pediátrico.

Desta forma, conclui-se que apesar dos profissionais relatarem alguns transtornos e desavenças com a presença dos acompanhantes, os benefícios da sua presença, para a criança e a equipe de enfermagem, superam. Portanto, o acompanhante precisa ser acolhido de forma que se sinta como sujeito fundamental para a melhoria na qualidade da assistência da criança hospitalizada.

\section{REFERÊNCIAS}

1. Pinto JP, Fernandes MG. Crescimento e desenvolvimento infantil. In: Fonseca AS, org. Enfermagem pediátrica. São Paulo: Martinari; 2013.

2. Oliveira SR. Assistência de enfermagem à criança e à família. In: Fonseca AS, org. Enfermagem pediátrica. São Paulo: Martinari; 2013.

3. Cunha MLR. Tomada de decisão da criança e família: visão da enfermagem. In: 2o Congresso Internacional Sabará de Especialidades Pediátricas; 2014 set. 12-14. São Paulo-SP: Blucher Medical Proceedings; 2014.

4. Jonas MF, Costa MADJ, Souza PTL, Pinto RNM, Morais GSN, Duarte MCS. O Lúdico como Estratégia de Comunicação para a Promoção do Cuidado Humanizado com a Criança Hospitalizada. Rev Bras Ciênc Saúde. 2013;17(4):393-400. https://doi.org/10.4034/ RBCS.2013.17.04.11

5. Gomes GC, Oliveira PK. Vivências da família no hospital durante a internação da criança. Rev Gaúcha Enferm. 2012;33(4):165-71. https://doi.org/10.1590/S1983-14472012000400021

6. Torquato IM, Collet NC, Dantas MS, Jonas MF, Trigueira JVS, Nogueira MF. Humanized care for admitted children: perception of caregivers. J Nurs UFPE on line. 2013;7(9):5541-9. https://doi. org/10.5205/reuol.3529-29105-1-SM.0709201323

7. Nicola GDO, Ilha S, Dias MV, Freitas HMB, Backes DS, Gomes GC. Perceptions of the caregiver Family member about playful care of the hospitalized child. J Nurs UFPE on line. 2014;8(4):981-6. https:// doi.org/10.5205/reuol.5829-50065-1-ED-1.0804201425

8. Lemos I, Oliveira J, Gomes E, Silva K, Silva P, Fernandes G. Brinquedo terapêutico no procedimento de punção venosa: estratégia para reduzir alterações comportamentais. Rev Cuid. 2016;7(1):1163-70. https://doi.org/10.15649/cuidarte.v7i1.303
9. Soares JD'AD, Brito RS, Carvalho JBL. A presença do pai/ acompanhante no âmbito hospitalar: revisão integrativa. J Nurs UFPE on line. 2014;8(7):2095-106. https://doi.org/10.5205/ reuol.5963-51246-1-RV.0807201435

10. Bretas, TCS, Silva dos PS, Prado PF, Andrade, FM, Versiani, CC. O conhecimento do familiar/acompanhante pediátrico acerca da infecção hospitalar. Cienc. Saude (Porto Alegre). 2013;6(2):78-84. https://doi.org/10.15448/1983-652X.2013.2.12067

11. Soares NTI, Tacla MTGM. Experience of nursing staff facing the hospitalization of burned children. Invest Educ Enferm. 2014;32(1):49-59.

12. Melo EMOP, Ferreira PL, Lima RAG, Mello DF. The involvement of parents in the healthcare provided to hospitalzed children. Rev. Latino-Am Enfermagem. 2014;22(3):432-9. https://doi. org/10.1590/0104-1169.3308.2434

13. Gil AC. Como elaborar projetos de pesquisa. 4ae ed. São Paulo: Atlas; 2002.

14. Minayo MCS. O desafio do conhecimento: pesquisa qualitativa em saúde. 12ª ed. São Paulo: Hucitec; 2010.

15. Silva RCC, Sampaio JA, Ferreira AGN, Ximenes Neto FRG, Pinheiro PNC. Sentimentos das mães durante hospitalização dos filhos: estudo qualitativo. Rev Soc Bras Enferm Ped. 2010;10(1): 23-30.

16. Santos PM, Silva LF, Depianti JRB, Cursino EG, Ribeiro CA. Os cuidados de enfermagem na percepção da criança hospitalizada. Rev Bras Enferm. 2016;69(4):646-53. https://doi.org/10.1590/0034$7167.2016690405 \mathrm{i}$

17. Marques CDC, Lima MF, Malaquias TSM, Waidman MAP, Higarashi IH. O cuidador familiar da criança hospitalizada na visão da equipe de enfermagem. Cienc Cuid Saúde. 2014;13(3):541-8. https://doi. org/10.4025/cienccuidsaude.v13i3.22133

18. Facio BC, Matsuda LM, Higarashi IH. Internação conjunta pediátrica: compreendendo a negociação enfermeiro-acompanhante. Rev Eletrônica Enferm. 2013;15(2):447-53.

19. Bélanger L; Desmartis M; Coulombe M. Barriers and facilitators to family participation in the care of their hospitalized loved ones. Patiente Exper J. 2018;5(1):56-65.

20. Vieira PB, Danielski K. O compartilhamento do cuidado entre a equipe de enfermagem e os pais de crianças hospitalizadas. Rev Cient CENSUPEG. 2013;2:110-19.

21. Pimenta EAG, Soares CCD, Pinto RNM, Souza PTL, Lima ET, Reichert APS. Experience of accompanying father during daughter's hospitalization. J Nurs UFPE on line. 2014;8(6):1814-9. https://doi. org/10.5205/reuol.5876-50610-1-SM.0806201448

22. Faccioli SC, Tacla MTGM, Cândido LK, Ferrari RAP, Gabani FL. Punção venosa periférica: o olhar da criança hospitalizada. Rev Eletr Acervo Saúde. 2017;9(4):1130-4.

23. Melo EMOP, Ferreira PL, Lima RAG, Mello DF. Envolvimento dos pais nos cuidados de saúde de crianças hospitalizadas. Rev LatinoAM Enferm. 2014;22(3):432-9. https://doi.org/10.1590/01041169.3308 .2434 